\title{
Направления и формы трансформации избирательного процесса и технологий (на примере Дальнего Востока)
}

\begin{abstract}
Введение
Ключевой особенностью современных социально-экономических и общественно-политических процессов является стремительное развитие информационно-коммуникативных систем и цифровых технологий, тотальная "цифровизация" публично-властного и частного взаимодействия. Значимость процессов цифровизации, их влияние на трансформацию общественных отношений является ведущим трендом в действующем сощиально-гуманитарном дискурсе. В работе как отечественных, так и зарубежных исследователей обсуждается целый комплекс проблематик, связных с последним (Р. И.Дремлюга, А. Ю. Мамычев, О. А.Дремлюга, Ю. С. Матюк, М. Расселл, Л. Замфрир и др.). Сам термин "цифровизация" в более широком значении понимается как "общемировой тренд развития общества, в том числе его социально-экономического устройства, который основан на преобразовании в цифровую форму информации и приводит к повышению эффективности экономики и улучшению качества жизни" [23; 25, с. 12].

Однако, очевидно, что внедрение цифровых технологий реализуется не только в экономическом секторе, но и существенно влияет на все сферы жизнедеятельности современного общества (политика, право, культуру, энергетику и проч.). Например, в рамках политического процесса ключевым на повестке дня является применение цифрровых технологий в избирательном процессе для повышения транспарентности (открытости), мобильности и удобства последнего. Предполагается, что использование "цифровых электронных систем" в политическом процессе содержит потенциальную возможность повышения эффективности реализации принципов и норм в электоральной сфере: равенства, прозрачности, доступности, тайны голосования, адекватного учёта волеизъявления избирателей, действенности общественного контроля и мониторинга, легитимации итогов голосования и т.д. Без сомнения, "всеобщие и свободные выборы в постиндустриальном обществе рассматриваются как "ядро" демократии", а потому нормативно-правовое регулирование информационно-технических инструментов волеизъявления граждан особенно актуально в XXI в.
\end{abstract}

\section{Теоретико-методологические основания исследования и обзор подходов}

Целью настоящей работы является исследование направлений и форм трансформации избирательного процесса и технологий под воздействием цифровой трансформации общественных систем. Для достижения указанной цели необходимо провести анализ социально-политической динамики в условиях цифровых преобразований политических процессов, в том числе на примере Дальнего Востока, позиций исследователей по обозначенному вопросу, а

\author{
(C) Катрин E. B., 2021
}

КАТРИН Екатерина Васильевна, ассистент кафедры конституционного и административного права Владивостокского государственного университета экономики и сервиса (2. Владивосток). E-mail: katrin.ev@list.ru

Работа выполнена при финансовой поддержке Гранта Президента РФ № НШ-2668-2020.6 "Национально-культурные и цифровые тренды социально-экономического и политико-правового развития Российской Федерации в XXI веке". 
также экспертный опрос в целях выявления перспектив применения цифровых систем и технологий в избирательном процессе на Дальнем Востоке.

Обращаясь к исследованиям авторов, специализирующихся по указанной проблеме, следует отметить мнение Закускина А.А., Зайцевой Ю.А., Тимербулатовой Н. Э., Бачило И. Л., Шмакова М. А., Белоконева С. Ю., Васильева М. С., Титова В. В., Зотова В. Б., Косарина С. П., Коломина А. К., Колегова И. В., Давыдова К. В., Степанченко К. П., Кузенковой Д. С., Кудрявцевой А. С., Кузенкова П. С., описывающих в своих работах особенности и возможности применения информационных технологий в политическом процессе $[2$, с. $82-83 ; 4 ; 11 ; 12$, с. $277-282 ; 13$, с. $42-48 ; 14 ; 20]$. Опыт применения дистанционных форм волеизъявления отражаются в исследованиях Абрамова Ю. И., Белоконева С. Ю., Чистова И. И., Булаева Н. И., Рулева М. С. [1, с. 3-10; 3, с. 69-77; 7; 19]. О влиянии цифровой трансформации на участие граждан в электоральном процессе писали Ближевская Д. А., Семенихин А. К., Кулаковой Н. Н., Болтаевская Ю., Демушина О. Н. [5; 6; 10, c. 132-151]. Чимаров Н. С. исследовал вопросы, входящие в правовую основу экспериментального проекта "Дистанционное электронное голосование" на выборах 8 сентября 2019 г. в Московскую городскую Думу седьмого созыва [22, c. 21-25].

Настоящее исследование опирается на общефилософрские методы и приёмы исследования, такие как герменевтический, системный, диспозитивный, а также арсенал общенаучных (логических) методов: анализ, синтез, индукция и дедукция. В качестве частнонаучной (дисциплинарной) методологии использовались сравнительно-политический и контент-анализ, а также методы политического моделирования и прогнозирования. В качестве эмпирической основы выступили конкретные кейсы использования электронных средств волеизъявления, учета мнений граждан. В работе обобщаются научно-практические исследования в сфере цифровизации избирательного процесса, экспертные оценки и различные аналитические материалы. В рамках исследования заявленной проблематики в контексте общественно-политических процессов был использован экспертный опрос.

\section{Основная часть}

Ряд современных политических экспертов и исследователей, с позицией которых мы согласны, фриксируют и аргументируют, что развитие цифровых технологий ведёт к кардинальным трансформациям общества, политического процесса и, в частности, избирательного процесса, форм, инструментов и способов реализации избирательных прав. В этой связи для структурного и содержательного описания ключевых трендов трансформации избирательного процесса под воздействием цифровых технологий представим и рассмотрим преставления пяти основных направлений таковой трансформации.

Первое направление связано с организационными аспектами трансформации политического процесса, о которых председатель Центризбиркома Элла Памфилова упоминала в ходе встречи с Президентом России 24 января 2020 г. По её словам, на сегодняшний день вопросы организации политического процесса постепенно, но уверенно развиваются в условиях применения новых технологий, в то время как всего несколько лет назад использование на избирательных участках систем непосредственного наблюдения за процессом проведения выборов и автоматизированных комплексов обработки избирательных бюллетеней считалось новшеством в электоральном процессе [8]. Теперь же, цифровые технологии и системы политического волеизъявления широко используются в большинстве субъектов страны [6; 9].

Так, государственная автоматизированная система "Выборы" создавалась на основании Указов Президента РФ от 23.08.1994 г. № 1723 "О разработке и создании Государственной автоматизированной системы Российской Федерации "Выборы"' и от 28.02.1995 г. № 227 "Об обеспечении создания, фрункционирования и развития Государственной автоматизированной системы Российской Федерации "Выборы"'. Упомянутые Указы стали также основанием для создания Федерального центра информатизации (ФЦИ) при Центральной избирательной комиссии Российской Федерации для организационного, информационного и методического обеспечения автоматизированной системы "Выборы" [9]. 
Рассматриваемая система стала первым информационным политическим инструментом федерального уровня, основательно проникшим в региональный и муниципальный уровни власти, в связи с чем возникла необходимость решения значимой в целях успешной реализаџии проекта задачи - адаптации ГАС "Выборы" к потребностям отдельных регионов страны. Приемлемый вариант решения обозначенного вопроса предполагал установление отношений с руководством субъектов, вследствие чего в период с 1997 по 1999 гг. были подписаны генеральные соглашения о совместном использовании системы с главами семидесяти регионов страны, в частности, и в пределах Дальнего Востока.

В данных соглашениях устанавливалась ответственность за поддержание в рабочем состоянии комплексов средств автоматизации (КСА) региональных фрагментов системы, а также регламентировалось проведение работ по интегрированию ГАС "Выборы" с иными цифровыми системами. Процессы по сопряжению системы в единое пространство включали научно-технические решения, а также организационные меры, связанные с предоставлением ресурсов федеральным органам власти, по причине которых были подписаны соответствующие соглашения с обширным перечнем ведомств и с Управлением Правительственной информации Аппарата Правительства РФ. Таким образом, с появлением ГАС "Выборы" в российском информационном пространстве были созданы прикладные возможности для становления цифрового политического общества.

Во второл направлении, как правило, обсуждаются технические аспекты цифровизации электорального процесса, к которым относится интеграция ГАС "Выборы" с другими техническими решениями и общероссийской информационной инфраструктурой в целом, чего невозможно было бы добиться без нормативного закрепления. Так, в становлении государственной системы значимым инструментом послужил указ Президента РФ от 28.02.1995 г. № 227 "Об обеспечении создания, фонкционирования и развития Государственной автоматизированной системы Российской Федерации "Выборы"'", в рамках которого решались вопросы финансового и материального обеспечения в целях установки программно-технических комплексов системы к фредеральным выборам депутатов Госдумы второго созыва 17.12.1995 г. К указанной дате было установлено порядка трёх тысяч терминалов ГАС "Выборы" в 87 субъектах федерации, несмотря на ограниченные сроки реализации идеи [21].

Государственная автоматизированная система "Выборы" была создана в целях реализации цифровых процессов в период подготовки и проведения выборов и комплексного решения задач, связанных с организацией политического процесса на каждом из этапов - от соответствующих мер по планированию и учёта избирателей до подведения итогов выборов и последующей обработки статистических данных. Вместе с тем в целях интегрирования ГАС "Выборы" системой предусмотрена фрункция согласования работы избирательных комиссий на каждом уровне $[4 ; 20]$.

Таким образом, система была создана в качестве комплексного решения автоматизации политических процессов, реализованных в цифровых, связанных специализированными каналами связи, центрах избирательных комиссий. При этом ГАС "Выборы" содержал ряд функциональных комплексов задач (ФКЗ), таких как "Избиратель" (для автоматизации учёта избирателей), "Территория" и "Кандидат" (в целях механизации избирательных процессов), "Кадры" (по учёту кадрового состава избирательных комиссий), "Контроль фонансов" (в целях учёта и контроля использования избирательных фондов), "Право" (для представления информации по правовому законодательству), "Итоги" и другие. Кроме того, исследуемая автоматизированная система стала первым в мире техническим решением, предоставившим уже в течение суток после проведения выборов итоги голосования в сети "Интернет".

В последующем ГАС "Выборы" технически совершенствовалась в целях улучшения работы системы. Всего с начала создания государственной автоматизированной системы было применено 83 технических комплекса в избирательных комиссиях субъектов страны, 2726 - в территориальных комиссиях, в то же время автоматизированные средства подсчёта голосов были установлены в 5566 участковых избирательных комиссиях, а технические комплексы обработки избирательных бюллетеней (КОИБ) использовались в 
76 субъектах фредерации, несколько из которых - на Дальнем Востоке. Кроме КОИБов целесообразно упомянуть экспериментальный проект "Мобильный избиратель", послуживший достойной заменой традиционных открепительных $[11 ; 12$, с. 277-282; 13, с. 42-48; 14]. Следовательно, всего за двадцать лет в период развития ГАС "Выборы" были реализованы значительные преобразования технической составляющей автоматизированного решения.

Следующим, третьим направлениел трансформации избирательного процесса следует обозначить новые формы социального взаимодействия, преимущественно путём применения сетевых инструментов (к примеру, социальных сетей), с помощью которых реализуется ряд задач, необходимых для популяризации, информатизации, повышения доверия электоров и мобилизации электората. Указанные вопросы интересуют на сегодняшний день уже не только политические партии, но и общественные объединения, некоммерческие организации, институты государственной власти [2, с. 82-83].

Так, Федеральным законом от 02.05.2006 г. № 59-Ф3 "О порядке рассмотрения обращений граждан Российской Федерации" была установлена возможность әлектронного обращения граждан в государственные органы и органы местного самоуправления наравне с непосредственным личным обращением, что позволило направлять и получать обратную связь в кратчайшие сроки. При этом в качестве форм такого обращения возможно отметить направления в адрес электронной почты, онлайн-приёмные непосредственно на сайтах, Интернет-порталы и электронные терминалы. Кроме того, большинство государственных органов имеют активные аккаунты в актуальных, востребованных социальных сетях и сетевых платформах (ВКонтакте, Facebook, Instagram, YouTube и другие), в которых нередко также возможно обратиться с вопросом, входящим в компетенцию соответствующего ведомства.

В свою очередь группы и отдельные участники политических отношений реализуют собственные решения, в том числе и ввиду сильного влияния нарративов Интернет-пространства, что, в частности, подтверждается событиями, связанными с недавними протестными мероприятиями. Ярким примером на Дальнем Востоке является проведение митингов в Хабаровском крае, основанием которых послужил арест губернатора - согласно данным аналитики сервиса "Google Trends" с 13.07. до 14.08 информационный протестный поток содержит ряд пиковых значений с семидневными циклами регрессии, поддерживаемыми путём провокации активности на каналах социальных сетей, преимущественно "Телеграм-каналов" [24]. Предпосылки, результаты и последствия данной акции подробно описаны в работе Нагорняк К. И. [15, c. 60-77].

Четвёртое направление трансформации отражает форму волеизъявления граждан - от классического голосования на избирательных участках до участия в выборах посредством использования сети "Интернет".

Как уже упоминалось, Государственная автоматизированная система "Выборы" начала своё становление ещё в 1996 г., после чего электорам представилась возможность отойти от традиционного волеизъявления на бумажных носителях к голосованию посредством использования цифровых систем и технологий, таких как комплексы обработки избирательных бюллетеней и комплексы для электронного голосования. Данное новшество позволило обеспечить высокую скорость автоматического сбора бюллетеней и подсчёта голосов (исключение необходимости ручной обработки бюллетеней предоставило возможность избежать ошибки человеческого фрактора), а также наблюдение за процессом голосования в режиме текущего времени.

Следующим значимым шагом цифровизации политического процесса послужило применение системы "Мобильный избиратель", которая заменила традиционные открепительные, предоставив таким образом возможность голосовать в любом субъекте страны на цифровом избирательном участке, то есть географическую свободу для избирателей. Данный способ голосования впервые был применен на выборах глав субъектов и депутатов Законодательных собраний 10 сентября 2017 г. в 20 субъектах Российской Федерации. А уже в 2018 г. более пяти с половиной миллионов избирателей использовали возможность открепления по месту фактического проживания, половина из них - посредством использования портала "Госуслуги" [1, с. 3-10; 3, с. 69-77; 7; 19]. 
Кроме того, перспективным решением, по мнению экспертов, является применение дистанционных форм участия в политическом процессе с использованием Интернет-систем. Рассматриваемая технология была применена в целях участия граждан Москвы и Нижегородской области в голосовании по поправкам в Конституцию [16], основанием чего послужила апробация системы дистанционного электронного голосования в Федеральном законе от 23.05.2020 г. № 154-Ф3 "О внесении изменений в отдельные законодательные акты Российской Федерации", утверждённая ввиду ограничений, связанных с всемирной пандемией 2020 г. Указанный закон предусматривал две формы дистанционного участия, а именно: электронная (при регистрации на портале "mos.ru") и посредством почтового отправления [22, c. 21-25]. В то же время эксперты отмечают, что применение систем дистанционного электронного голосования должно учитывать один из важнейших аспектов данной формы трансформации политического процесса - обеспечение доверия электоров к результатам упомянутого голосования [5; 6; 10, с. 132-151].

В рамках исследования обозначенного вопроса был осуществлен әкспертный опрос на Дальнем Востоке представителей Избирательной комиссии Приморского края, политических экспертов и исследователей. По мнению последних, использование дистанционных электронных систем и технологий в электоральном процессе может повлиять положительным образом на показатели гражданской активности населения, а в дальнейшем постепенно повысить доверие избирателей. Однако в оценке экспертов отмечалось, что на сегодняшний день практика применения дистанџионных форм участия в избирательном процессе на Дальнем Востоке (в частности, в пределах Приморского края) отсутствует в связи с необходимостью закрепления на законодательном уровне [18].

Последний аспект, исследуемый в рамках настоящей работы, отражает совершенствование законодательной базы, регулирующей применение цифрровых систем в избирательном процессе. Первостепенно целесообразно обозначить правовую основу становления цифровой политической трансдрормации, а именно: Конституция Российской Федерации, Указ Президента РФ от 21.09.1993 г. № 1400 "О поэтапной конституционной реформе в Российской Федерации", Федеральный закон от 06.12.1994 г. № 56-Ф3 "Об основных гарантиях избирательных прав граждан Российской Федерации". Затем закрепление возможности использования государственной автоматизированной системы "Выборы" отразилось в положениях Концепции создания ГАС "Выборы". Последующее совершенствование системы происходило на основании Федерального закона "О государственной автоматизированной системе Российской Федеращии "Выборы"' от 10 января 2003 г. № 20-ФЗ, при этом с учётом актуального плана совершенствования системы [17].

Из наиболее значимых изменений в законодательном закреплении цифровой трансформации политических процессов последних лет целесообразно отметить подписание Президентом Российской Федерации 23 мая 2020 г. законов по совершенствованию процедуры проведения дистанционного электронного голосования: Федерального закона № 154-Ф3 "О внесении изменений в отдельные законодательные акты Российской Федерации", Федерального закона № 152-Ф3 "О проведении эксперимента по организации и осуществлению дистанционного электронного голосования в городе федерального значения Москве" и Федерального закона № 151-ФЗ "О продлении на 2020 г. эксперимента по голосованию на цифровых избирательных участках на дополнительных выборах депутатов Государственной Думы Федерального Собрания Российской Федерации седьмого созыва и выборах в органы государственной власти субъектов Российской Федерации". Первый из упомянутых нормативных актов вводит определение дефиниции "дистанционное электронное голосование", увеличивает возможности проведения голосования без необходимости непосредственного посещения избирательного участка посредством почтового отправления или использования электронного способа участия в выборах. Также указанный закон устанавливает запрет на участие в выборах в качестве кандидатов отдельным категориям лиц.

В свою очередь в Федеральном законе от 23.05.2020 г. № 152-Ф3 "О проведении эксперимента по организации и осуществлению дистанционного электронного голосования в городе федерального значения Москве" опреде- 
ляются условия применения новых цифровых систем и технологий, а также организационно-правовая основа тестового использования инструментов дистанционного электронного голосования в 2020-2021 гг. в г. Москва совместно с проведением выборов в традиционном формате, в связи с чем избиратели имели право выбирать формат участия в выборах самостоятельно.

Согласно третьему Федеральному закону № 151-Ф3 "О продлении на 2020 г. эксперимента по голосованию на цифровых избирательных участках на дополнительных выборах депутатов Государственной Думы Федерального Собрания Российской Федерации седымого созыва и выборах в органы государственной власти субъектов Российской Федерации" открывается возможность участия в выборах на местах, специально оборудованных цифровыми избирательными участками, в случаях, если избиратель находится вне постоянного места жительства в день голосования, но в пределах территории соответствующего субъекта. Также закон устанавливает порядок подачи жалоб на решения должностных лиц и вопросы финансового обеспечения проведения выборов на цифровых избирательных участках.

По мнению заместителя председателя Центральной избирательной комиссии Н. И. Булаева, региональные органы законодательной и исполнительной власти дали положительную оценку в отношении идей применения дистанционных форм волеизъявления, и с учётом экспертных замечаний и предложений бала подготовлена итоговая редакция упомянутых законопроектов [21].

\section{Выводы}

В заключение целесообразно отметить следующее. Цифровая трансформация общества конца XIX - начала XXI вв. фрундаментальным образом повлияла на отдельные аспекты политических процессов общества и государства. $\mathcal{K}$ таковым целесообразно отнести организационные, технические и правовые аспекты трансформации политического процесса, фрорму взаимодействия государства, общества и отдельных граждан, влияние на политическую культуру и преобразования в способах и методах волеизъявления граждан - от классического голосования на избирательных участках до участия в выборах посредством использования џифровых систем и технологий.

По результатам настоящего исследования достигнута её цель - анализ направлений и форм трансформации избирательных технологий, а также обозначенные в рамках настоящей работы задачи: исследование конфрликтов и противоречий социально-политической динамики на примере Дальнего Востока, позиций исследователей по обозначенному вопросу, а также экспертный опрос в целях выявления положения в сфрере применения цифровых систем и технологий избирательного процесса на Дальнем Востоке. Теоретическая значимость исследования заключается в совершенствовании концептуальных основ теории цифровой трансформации избирательного процесса в Российской Федерации, практическая значимость - в развитии политических инструментов совершенствования цифровизации электорального процесса и технологий, а также возможности их применения в практической деятельности и учебных курсах. Дальнейшие исследования по обозначенной проблеме предполагается направить в отношении поиска решений потенциальных проблем и рисков внедрения дистанционных технологий в избирательный процесс.

\section{Литература}

1. Абрамов Ю. И. Москва, выборы, эксперимент // Выборы: теория и практика. 2019. Вып. 2 (50). С. 3-10.

2. Бачило И.Л., Шмаков М.А. О трансформации институтов "государство" и "право" в инфрормационном обществе // Государство и право. 2017. № 11. С.82-83.

3. Белоконев С.Ю., Чистов И.И. Электронное голосование как перспектива политического процесса: возможности и ограничения "цифровой политики" // Гуманитарные науки. Вестник Финансового университета. 2017. № 5. С. 69-77.

4. Белоконев С.Ю., Васильев М.С., Титов В.В. Цифровые технологии в современных избирательных кампаниях: особенности применения // Глобализация и цифровое общество: сборник научных статей. М., 2019. С. 51-57. 
5. Ближевская Д. А., Семенихин А.К., Кулакова Н.Н. Влияние цифровых технологий на участие граждан в избирательном процессе // Конференция "Ломоносов 2018": сборник статей, [Электронный ресурc]. URL: https://lomonosov-msu.ru/archive/ Lomonosov_2018/data/13476/77041_uid249575_report.pdf (дата обращения: 05.04.2021).

6. Болтаевская Ю. Цифровизация избирательного процесса: "свобода, какой не было раньше" // Забайкальский рабочий. 2019. № 43.

7. Булаев Н.И. "Мобильный избиратель" имеет потенциал для развития // Ria. ru, [Электронный ресурс]. URL: https://ria.ru/20180822/1526992735.html (дата обращения: 05.04.2021).

8. Глава ЦИК рассказала о проработке вопроса о дистанционном голосовании // Парламентская газета, [Электронный ресурc]. URL: https://www.pnp.ru/politics/glavacik-rasskazala-o-prorabotke-voprosa-o-distancionnom-golosovanii.html (дата обращения: 05.04.2021).

9. Государственная автоматизированная система Российской Федерации "Выборы" // Официальный интернет-портал правовой информации, [Электронный ресурc]. URL: https://digital.gov.ru/ru/activity/govservices/infosystems/2/ (дата обращения: 05.04.2021).

10. Демушина О. Н. Факторы повышения эффективности электронного участия граждан // Ars administrandi. Искусство управления. 2017. Вып. 2. С. 132-151.

11. Зайцева Ю. А., Тимербулатова Н. Э. Использование информационно-коммуникационных технологий в избирательном процессе // Устойчивое развитие науки и образования. 2017. Вып. 7. С. 187-193.

12. Закускин А.А. Внедрение электронных технологий в российский избирательный процесс // Вестник марийского государственного университета. 2019. Вып. 3 (19). C. $277-282$.

13. Зотов В.Б., Косарин С.П. Методология организации и проведения электронного голосования при выборах депутатов // Муниципальная академия. 2019. Вып. 3. C. $42-48$.

14. Коломин А.К., Колегов И.В., Давыдов К.В. Внедрение новых технологий в избирательный процесс: проблемы и перспективы // Современные исследования. 2018. Вып. 12 (16). С. 255-257.

15. Нагорняк К.И. Активность оппозиционных Telegram-каналов и поведенческий фрактор пользователей Google как метод исследования протестов Белоруссии 2020 года // Вестник РУНД. 2021. Вып. 23. С. 60-77.

16. О внесении изменений в отдельные законодательные акты Российской Федерации: федер. закон от от 23.05.2020 г. № 154-ФЗ // СПС "Консультант Плюс", [Электронный ресурc]. URL: http://www.consultant.ru/document/cons_doc_LAW_353206/ (дата обращения: 05.04.2021).

17. О Государственной автоматизированной системе Российской Федеращии "Выборы": Федеральный закон от 10.01.2003 № 20-ФЗ (ред. от 29.05.2019) // СПС "Консультант Плюс", [Электронный ресурс]. URL: http://www.consultant.ru/document/cons_doc_ LAW_40419/ (дата обращения: 05.04.2021).

18. Результаты опроса заместителя председателя Избирательной комиссии Приморского края // Google forms, [Электронный ресурc]. URL: https://forms.gle/ J3mSZKeEAiMbyv5f9 (дата обращения: 05.04.2021).

19. Рулев М. С. Дистанционное электронное голосование: проблемы и перспективы развития в российской федерации // Выборы: теория и практика. 2018. Вып. 1 (53). C. $8-13$.

20. Степанченко К. П., Кузенкова Д. С., Кудрявцева А. С., Кузенков П. С. Преимущества и недостатки использования цифровых технологий в процессе выборов // VII межрегиональный форум: сборник материалов. Киров: Изд-во ООО "Издательство "Радуга-ПРЕСС"'", 2017. С. 145-149.

21. Центральная избирательная комиссия Российской Федерации // Официальный интернет-портал правовой информации, [Электронный ресурc]. URL: http://www. cikrf.ru/gas/real_prog.php (дата обращения: 05.04.2021).

22. Чимаров Н.С. Правовая основа экспериментального проекта "Дистанционное электронное голосование" на выборах 8 сентября 2019 года в Московскую городскую Думу седьмого созыва // Вестник Санкт-Петербургской юридической академии. 2019. Вып. 4 (45). С. 21-25.

23. Dremliuga R.I., Mamychev Alexey YU., Dremliuga O.A., Matyuk YU.S. Artificial intelligence as a subject of law: pros and cons // Elibrary, [Электронный pecypc]. URL: https://elibrary.ru/item.asp?id=41788789 (дата обращения: 05.04.2021).

24. Google Trends - official website by Google that analyzes the popularity of top search queries in Google Search // Google trends, [Электронный pecypc]. URL: https:// trends.google.ru/trends/?geo=RU (дата обращения: 05.04.2021).

25. Russell M., Zamfir L. Digital technology in elections. Efficiency ver-sus credibility // European Parliamentary Research Service. September, 2018. P. 12. 


\section{Транслитерация по ГОСТ 7.79-2000 Система Б}

1. Abramov YU. I. Moskva, vybory, ehksperiment // Vybory: teoriya i praktika. 2019. Vyp. 2 (50). S. 3-10.

2. Bachilo I.L., SHmakov M.A. O transformatsii institutov "gosudarstvo" i "pravo" v informatsionnom obshhestve // Gosudarstvo i pravo. 2017. № 11. S.82-83.

3. Belokonev S.YU., CHistov I.I. EHlektronnoe golosovanie kak perspektiva politicheskogo protsessa: vozmozhnosti i ogranicheniya "tsifrovoj politiki" // Gumanitarnye nauki. Vestnik Finansovogo universiteta. 2017. № 5. S. 69-77.

4. Belokonev S.YU., Vasil'ev M.S., Titov V.V. TSifrovye tekhnologii v sovremennykh izbiratel'nykh kampaniyakh: osobennosti primeneniya // Globalizatsiya i tsifrovoe obshhestvo: sbornik nauchnykh statej. M., 2019. S. 51-57.

5. Blizhevskaya D. A., Semenikhin A.K., Kulakova N.N. Vliyanie tsifrovykh tekhnologij na uchastie grazhdan v izbiratel'nom protsesse // Konferentsiya "Lomonosov 2018": sbornik statej, [EHlektronnyj resurs]. URL: https://lomonosov-msu.ru/archive/Lomonosov_2018/data/13476/77041_uid249575_report.pdf (data obrashheniya: 05.04.2021).

6. Boltaevskaya YU. TSifrovizatsiya izbiratel'nogo protsessa: "svoboda, kakoj ne bylo ran'she" // Zabajkal'skij rabochij. 2019. № 43.

7. Bulaev N.I. "Mobil'nyj izbiratel"' imeet potentsial dlya razvitiya // Ria.ru, [EHlektronnyj resurs]. URL: https://ria.ru/20180822/1526992735.html (data obrashheniya: 05.04.2021).

8. Glava TSIK rasskazala o prorabotke voprosa o distantsionnom golosovanii // Parlamentskaya gazeta, [EHlektronnyj resurs]. URL: https://www.pnp.ru/politics/glava-cik-rasskazala-o-prorabotke-voprosa-o-distancionnom-golosovanii.html (data obrashheniya: 05.04.2021).

9. Gosudarstvennaya avtomatizirovannaya sistema Rossijskoj Federatsii "Vybory" // Ofitsial'nyj internet-portal pravovoj informatsii, [EHlektronnyj resurs]. URL: https://digital.gov.ru/ru/activity/govservices/infosystems/2/ (data obrashheniya: 05.04.2021).

10. Demushina O. N. Faktory povysheniya ehffektivnosti ehlektronnogo uchastiya grazhdan // Ars administrandi. Iskusstvo upravleniya. 2017. Vyp. 2. S. 132-151.

11. Zajtseva YU. A., Timerbulatova N. EH. Ispol'zovanie informatsionno-kommunikatsionnykh tekhnologij v izbiratel'nom protsesse // Ustojchivoe razvitie nauki i obrazovaniya. 2017. Vyp. 7. S. 187-193.

12. Zakuskin A.A. Vnedrenie ehlektronnykh tekhnologij v rossijskij izbiratel'nyj protsess // Vestnik marijskogo gosudarstvennogo universiteta. 2019. Vyp. 3 (19). S. 277-282.

13. Zotov V.B., Kosarin S.P. Metodologiya organizatsii i provedeniya ehlektronnogo golosovaniya pri vyborakh deputatov // Munitsipal'naya akademiya. 2019. Vyp. 3. S. 4248.

14. Kolomin A.K., Kolegov I.V., Davydov K.V. Vnedrenie novykh tekhnologij v izbiratel'nyj protsess: problemy i perspektivy // Sovremennye issledovaniya. 2018. Vyp. 12 (16). S. 255-257.

15. Nagornyak K.I. Aktivnost' oppozitsionnykh Telegram-kanalov i povedencheskij faktor pol'zovatelej Google kak metod issledovaniya protestov Belorussii 2020 goda // Vestnik RUND. 2021. Vyp. 23. S. 60-77.

16. O vnesenii izmenenij v otdel'nye zakonodatel'nye akty Rossijskoj Federatsii: feder. zakon ot ot 23.05.2020 g. № 154-FZ // SPS "Konsul'tant Plyus", [EHlektronnyj resurs]. URL: http://www.consultant.ru/document/cons_doc_LAW_353206/ (data obrashheniya: 05.04.2021).

17. O Gosudarstvennoj avtomatizirovannoj sisteme Rossijskoj Federatsii "Vybory": Federal'nyj zakon ot 10.01.2003 № 20-FZ (red. ot 29.05.2019) // SPS "Konsul'tant Plyus", [EHlektronnyj resurs]. URL: http://www.consultant.ru/document/cons_doc_LAW_40419/ (data obrashheniya: 05.04.2021).

18. Rezul'taty oprosa zamestitelya predsedatelya Izbiratel'noj komissii Primorskogo kraya // Google forms, [EHlektronnyj resurs]. URL: https://forms.gle/J3mSZKeEAiMbyv5f9 (data obrashheniya: 05.04.2021).

19. Rulev M. S. Distantsionnoe ehlektronnoe golosovanie: problemy i perspektivy razvitiya v rossijskoj federatsii // Vybory: teoriya i praktika. 2018. Vyp. 1 (53). S. 8-13.

20. Stepanchenko K. P., Kuzenkova D. S., Kudryavtseva A. S., Kuzenkov P. S. Preimushhestva i nedostatki ispol'zovaniya tsifrovykh tekhnologij v protsesse vyborov // VII mezhregional'nyj forum: sbornik materialov. Kirov: Izd-vo OOO "Izdatel'stvo "Raduga-PRESS"'", 2017. S. 145-149.

21. TSentral'naya izbiratel'naya komissiya Rossijskoj Federatsii // Ofitsial'nyj internet-portal pravovoj informatsii, [EHlektronnyj resurs]. URL: http://www.cikrf.ru/gas/real_ prog.php (data obrashheniya: 05.04.2021).

22. CHimarov N.S. Pravovaya osnova ehksperimental'nogo proekta "Distantsionnoe ehlektronnoe golosovanie" na vyborakh 8 sentyabrya 2019 goda v Moskovskuyu gorodskuyu Dumu sed'mogo sozyva // Vestnik Sankt-Peterburgskoj yuridicheskoj akademii. 2019. Vyp. 4 (45). S. 21-25. 
23. Dremliuga R.I., Mamychev Alexey YU., Dremliuga O.A., Matyuk YU.S. Artificial intelligence as a subject of law: pros and cons // Elibrary, [EHlektronnyj resurs]. URL: https://elibrary.ru/item.asp?id=41788789 (data obrashheniya: 05.04.2021).

24. Google Trends - official website by Google that analyzes the popularity of top search queries in Google Search // Google trends, [EHlektronnyj resurs]. URL: https:// trends.google.ru/trends/?geo=RU (data obrashheniya: 05.04.2021).

25. Russell M., Zamfir L. Digital technology in elections. Efficiency ver-sus credibility // European Parliamentary Research Service. September, 2018. P. 12.

Катрин Е. В. Направления и формы трансформации избирательного процесса и технологий (на примере Дальнего Востока).

В рамках настоящей работы исследованы направления трансформации электорального процесса и технологий под влиянием цифровизации общественных систем Российской Федерации, в частности, территории Дальнего Востока. В целях достижения обозначенных задач использованы общефилософрские методы, герменевтические, системные и диспозитивные приёмы исследования, общенаучные методы: анализ, синтез, индукция и дедукция, а также частнонаучная методология и методы политического моделирования и прогнозирования, экспертный опрос. По итогам проведённого исследования автор приходит к заключениям о характере направлений воздействия цифровизации политического процесса и технологий (организационных, технических, правовых аспектов трансформации электорального процесса), а также форм реализации избирательного права, конфликтов и противоречий, возникающих под воздействием преобразований в способах и методах волеизъявления граждан.

Ключевые слова: иибровизация, выборы, избирательный процесс, политический процесс, избирательнье технологии, трансфбормаиия избирательных технологий

Katrin E. V. Directions and forms of transformation of electoral process and technologies (on the example of the Far East).

Within the framework of this work, the directions of transformation of the electoral process and technologies under the influence of the digitalization of public systems of the Russian Federation, in particular, the territory of the Far East, have been investigated. In order to achieve the designated tasks, general philosophical methods, hermeneutic, systemic and dispositive research methods, general scientific methods: analysis, synthesis, induction and deduction, specific scientific methodology and methods of political modeling and forecasting, an expert survey were used. Based on the results of the study, the author comes to conclusions about the nature of the directions of the impact of digitalization of the political process and technologies (organizational, technical, legal aspects of the transformation of the electoral process), the forms of exercising electoral law, conflicts and contradictions arising under the influence of transformations in the ways and methods of expression of the will of citizens.

Key words: digitalization, elections, electoral process, political process, electoral technologies, transformation of electoral technologies

Для цитирования: Катрин Е. В. Направления и формы трансформации избирательного процесса и технологий (на примере Дальнего Востока) // Ойкумена. Регионоведческие исследования. 2021. № 4. C. 6-14. DOI: 10.24866/1998-6785/2021-4/6-14

For citation: Katrin E. V. Directions and forms of transformation of electoral process and technologies (on the example of the Far East) // Ojkumena. Regional researches. 2021. № 4. P. 6-14. DOI: 10.24866/1998-6785/2021-4/6-14 